\title{
A reconfiguração da tributação brasileira no contexto das Guerras Napoleônicas
}

\author{
por Angelo Alves Carrara
}

\begin{abstract}
The Napoleonic Wars had an extraordinary impact on the Portuguese Empire: the Portuguese Court moved from Lisbon to the capital of Brazil, Rio de Janeiro, in 1808. It was a unique phenomenon - the metropolis moved to the colony. This fact obviously was accompanied by absolutely essential measures for the maintenance of the state: the establishment of structures for the administration of tax collection. This took place on June 28, 1808, when a letter signed by the Prince Regent created the Royal Treasury and Board of Finance. In practice, the matters carried out previously by the Board of Finance abroad began to center on the new organ. Thus all matters related to the extraction, distribution, and administration of the Treasury in the Portuguese dominions in America, Africa and Asia, Azores and Madeira passed into the jurisdiction of the Royal Treasury. The results were immediate, and very unlike what generally occurred in times of war: In 1809 the revenues of the captaincy of Rio de Janeiro gave a jump. This paper studies the impacts of that period on the taxation of Brazil, in general, and the captaincy of Rio de Janeiro, in particular.
\end{abstract}

As guerras napoleônicas produziram um impacto extraordinário sobre o Império português: a Corte portuguesa transferiu-se de Lisboa para a capital do Estado do Brasil, Rio de Janeiro, em 1808. Foi um fenômeno único - a metrópole mudou-se para a colônia. Este fato obviamente foi acompanhado por algo absolutamente essencial para a manutenção do Estado: o estabelecimento das estruturas responsáveis pela administração da arrecadação tributária. Isto teve lugar em 28 de junho de 1808, quando uma carta firmada pelo príncipe regente criou a Real Fazenda e o Conselho de Fazenda. Na prática, os julgamentos anteriormente realizados pela Junta de Finanças no estrangeiro começaram a centralizar-se no novo órgão. Desse modo, passaram para a alçada da Real Fazenda todos os assuntos relacionados com a extração, distribuição e administração da Tesouraria nos domínios por- 
tugueses na América, África e Asia, Açores e Madeira. Além da administração centralizada, uma série de rotinas de contabilidade contribuíram para uma maior eficiência na arrecadação - incluindo a determinação dos dias de entrada nas arcas das quantidades percebidas. Os resultados foram imediatos e, muito diferentemente do que em geral ocorria em tempos de guerra, já em 1809 as receitas da capitania do Rio de Janeiro deram um salto. Este artigo estuda os impactos desse período sobre a fiscalidade do Brasil, em geral, e da capitania do Rio de Janeiro, em particular.

\section{A fiscalidade da CAPITANia do Rio De Janeiro No Final DO SÉCULO XVIII}

Noutro lugar destaquei que as fontes fiscais disponíveis para o Rio de Janeiro dificultam ao extremo à possibilidade de construir alguma série, mesmo que para uma única década, mesmo em se trantando da unidade administrativa que ao longo do XVIII manteve-se em segundo lugar em receitas e despesas. ${ }^{1}$ Este fato é mais importante do que a idéia propalada por Adriano Balbi da "política de segredo" dos assuntos fiscais e financeiros do governo português. Em suas palavras:

"Le plus grand mystère a toujours enveloppé tout ce qui a rapport aux finances du Portugal. Le secret, que était considéré par beaucoup de gouvernemens du siècle passé comme le palladium de leurs ressources et de leurs forces, était gardé si scrupuleusement en Portugal, que personne ne pouvait connaitre le montant des revenus de ce royaume, où la divulgation des documents relatifs à cet objet était considérée et punie comme un crime d'état. Le grand Pombal même n'a pas été exempt de ce préjugé, et lorsqu'il réduisit à système le chaos des finances en concentrant toutes les branches dans un seul trésor, il le répartit en quatre contadorias (sections) tout-à-fait indépendantes les unes des autres, pour empêcher chacun des quatre chefs de savoir les résultats généraux des trois autres contadorias. Il n'y avait que quatre seules personnes dans le royaume qui pussent connaître le bilan général: le roi, le marquis de Pombal, l'escrivão (le contrôleur général) et le thesoureiro mòr (le grand trésorier). Ce système de secret, qui ne sert qu'à couvrir les fraudes, à introduire, multiplier et perpétuer les abus, à inspirer la méfiance dans le public et à ôter tout crédit au

1 Angelo Alves Carrara, Receitas e despesas da Real Fazenda no Brasil. Minas Gerais, Bahia e Pernambuco, século XVIII (Juiz de Fora 2009). 
gouvernement, ce système de secret a été en grande partie la source du gaspillage et du désordre qui se sont introduits dans les finances du royaume, qui se trouvent dans le plus grand délabrement." ${ }^{2}$

Um século antes da transferência da Corte portuguesa para o Brasil, foi igualmente a capitania do Rio de Janeiro a que de modo mais intenso sofreu o impacto da nova conjuntura criada pela produção aurífera. Até os anos finais do século XVII esta capitania era fortemente deficitária, mas desde a primeira hora em que o ouro começou a ser dado à luz e posto em circulação, os rendimentos da Real Fazenda fluminense subiram de maneira astronômica. Todavia, diferentemente do que ocorreu em Minas, que desde o primeiro momento assistiu ao crescimento acelerado da agricultura e da pecuária de abastecimento dos núcleos mineradores, no Rio as fontes mais tradicionais de receita, como os dízimos e o estanco da pesca da baleia, mantiveram-se nos níveis do século anterior. Foi no comércio de importação de mercadorias do Reino sobre o qual incidiam impostos como o contrato dos vinhos e a dízima da Alfândega, que se deu a transformação. Este último imposto, por exemplo, como ocorreu em Bahia e em Pernambuco, alcançou a posição mais importante da fiscalidade fluminense em menos de uma década: em 1712 o valor da arrecadação desse tributo era de quase 18 contos, e em 1721 saltou para mais de 66 contos. Três anos depois já chegava a quase 100 contos de réis. ${ }^{3}$ Uma comparação entre a flutuação dos valores de arrematação do contrato dos dízimos e da dízima da Alfândega demonstra à perfeição a natureza da economia fluminense ao longo da primeira metade do século XVIII (tabela 1).

A tendência de forte alta dos valores da dízima da Alfândega, ou seja, do movimento de importação através do porto carioca, ao longo da primeira metade do século XVIII parece não ter exercido nesse período qualquer influência sobre a produção agrícola e pastoril, já que o valor dos dízimos mantiveram-se não apenas estáveis, mas nos mesmos patamares de um século antes. Além da Alfândega, os rendimentos da Casa da Moeda constituíam o segundo componente fundamental das finanças da capitania do Rio de Janeiro.

2 Adriano Balbi, Essai statistique du Royaume de Portugal et d'Algarve, comparé aux autres états de l'Europe (Paris 1822), p. 302.

3 Carrara, Receitas e despesas (nota 1), p. 49. 
TABELA 1: VALOR DO CONTRATO DOS DÍZIMOS E DA DÍZIMA DA AlfÂndega do Rio de Janeiro, 1710-1751 (EM \$ [RÉIS])

\begin{tabular}{l|l|l|l}
\hline Ano & Valor anual & Ano & Valor anual \\
\hline 1710 & 25.333 .333 & 1712 & 53.200 .000 \\
1722 & 16.000 .000 & 1721 & 66.600 .000 \\
1725 & 14.000 .000 & 1724 & 97.200 .000 \\
1726 & 16.900 .000 & & \\
1729 & 18.920 .000 & 1729 & 122.100 .000 \\
1732 & 19.210 .000 & 1732 & 107.600 .000 \\
1735 & 14.483 .333 & 1734 & 160.000 .000 \\
1739 & 19.205 .000 & 1738 & 194.805 .000 \\
1742 & 19.205 .000 & 1742 & 208.400 .000 \\
1745 & 22.400 .000 & 1745 & 209.600 .000 \\
1748 & 28.010 .000 & 1748 & 202.400 .000 \\
1751 & 24.020 .000 & 1751 & 202.400 .000 \\
\hline
\end{tabular}

Observação: os anos correspondem aos do primeiro ano da arrematação do contrato. Fonte: Carrara, Receitas e despesas (nota 1), pp. 50-53.

Para as décadas de 1770 e 1780, Dauril Alden foi o primeiro a avançar algumas conclusões a respeito da estrutura das receitas e despesas do Rio de Janeiro. Além disto, dedicou especial atenção às consequências fiscais da guerra com Espanha de 1774 e $1777 .{ }^{4}$ Os dados por ele extraídos de documentação muito fragmentada, quando comparados ao que se dispõe para outros anos, revelam uma relativa estabilidade dos valores nos últimos anos do período colonial: as receitas do Rio de Janeiro se situavam no patamar dos 450 contos de réis (tabela 2).

4 Dauril Alden, Royal government in colonial Brazil (Berkeley 1968), pp. 317-323. Com respeito à ausência de documentos fiscais, em particular balancetes de receitas e despesas, este autor também lamentou ter encontrado "not a single specimen of these balances". Sobre as consequências fiscais da guerra com Espanha, cf. ibidem, pp. 332347. 


\section{Tabela 2: Receitas da Capitania do Rio de Janeiro NA DÉCADA DE 1780 (EM \$)}

\begin{tabular}{|c|c|c|c|}
\hline Rubrica & $\mathbf{A}$ & B & $\mathbf{C}$ \\
\hline Casa da Moeda & 102.684 .365 & 102.684 .365 & 114.412 .054 \\
\hline Acréscimos das barras & 894.257 & 894.257 & \\
\hline Dízima da Alfândega & 136.875 .068 & 136.875 .068 & 136.918.143 \\
\hline Tomadias da Alfândega & 479.529 & 676.000 & \\
\hline Subsídio grande dos vinhos & 6.267 .229 & 6.267 .229 & 11.786 .547 \\
\hline Subsídio pequeno dos vinhos & 4.412 .312 & 4.412 .312 & 8.418 .978 \\
\hline Subsídio da aguardente do Reino e Ilhas & 4.239 .000 & 4.239 .000 & 4.803 .615 \\
\hline Subsídio do azeite doce & 2.900 .000 & 2.900 .000 & 1.633 .516 \\
\hline Imposto aplicado à guarda costa & 9.520 .958 & 9.520 .958 & 11.908 .235 \\
\hline Dízimos reais & 33.200 .050 & 33.200 .050 & 30.533 .333 \\
\hline Contrato pesca das baleias & 33.200 .000 & 11.800 .000 & 19.200 .000 \\
\hline Contrato Sal & 32.000 .000 & 28.081 .000 & 30.400 .000 \\
\hline Subsídio da aguardente da terra & 4.706 .666 & 4.511 .000 & 4.540 .000 \\
\hline Passagens dos rios Paraíba e Parahibuna & 13.093.333 & 13.093 .333 & 10.945 .920 \\
\hline Passagens rio São João & 175.333 & 175.333 & 156.000 \\
\hline Guindastes da Alfândega & 136.129 & 136.129 & \\
\hline Equivalente do contrato do tabaco & 15.698 .814 & 13.153 .000 & 12.988 .318 \\
\hline Direito dos escravos que vão para Minas & 15.403 .500 & 16.063 .000 & 13.342 .500 \\
\hline Direitos de 80 réis em cada alqueire de sal & 11.739 .600 & 6.784 .000 & 8.059 .730 \\
\hline Dízima da Chancelaria & 1.136 .268 & 1.136 .268 & 866.670 \\
\hline $\begin{array}{l}\text { Novos direitos das provisões de cartas de } \\
\text { seguro }\end{array}$ & 37.220 & 45.000 & 141.240 \\
\hline Novos direitos de provisões de mercês & 105.600 & 71.000 & \\
\hline Donativos de ofícios & 7.996 .105 & 9.028 .000 & 1.094 .210 \\
\hline Novos direitos de ofícios & 1.511 .294 & 1.511 .294 & \\
\hline Foros e alugéis da marinha & 2.070 .328 & 2.070 .328 & 2.178 .445 \\
\hline
\end{tabular}




\begin{tabular}{l|c|c|r} 
Rubrica & A & B & \multicolumn{1}{|c}{ C } \\
\hline $\begin{array}{l}\text { Bens próprios da Coroa } \\
\begin{array}{l}\text { Produtos dos gêneros vendidos nos } \\
\text { armazéns }\end{array}\end{array}$ & 145.600 & 145.600 & 52.800 \\
$\begin{array}{l}\text { Aluguel do armazém da pólvora da ilha } \\
\text { de Santa Bárbara }\end{array}$ & 523.200 & 523.200 & 5730.990 \\
$\begin{array}{l}\text { Recibo do depositário dos confiscos } \\
\text { Subsídio literário }\end{array}$ & & & 11.549 .125 \\
Receitas extraordinárias & & & \\
\hline Total & & & 1.394 .794 \\
\hline
\end{tabular}

Observações: em cursiva os tributos existentes em 1700; há uma diferença de $\$ 6.363 .383$ entre o total total apresentado pelo documento A e o cálculo correto das receitas.

FonTes: A: "Ramos que estabelecem a riqueza completa da Tesouraria Geral do Rio de Janeiro e praças subjacentes", constante das "Memórias públicas e econômicas da cidade de São Sebastião do rio de Janeiro para uso do vice-rei Luís de Vasconcelos, por observação curiosa dos anos de 1779 até o de 1789": Revista do Instituto Histórico e Geográfico Brasileiro 47, 1 (1884), p. 41; B: "Mapa geral do rendimento e despesa, [...] de um ano da Tesouraria Geral do Rio de Janeiro, calculado no que foi possível por um ano médio dos primeiros dez, depois do estabelecimento da dita Tesouraria [...] regulado pelo que se observou em outros anos, em que esta capitania esteve em sossego" [ ca. maio de 1781]: Revista do Instituto Histórico e Geográfico Brasileiro 51, 2 (1888), pp. 195-197; C: Arquivo Histórico do Tribunal de Contas de Lisboa, livro 4044, 1785.

Os números dessa década de 1780 não parecem diferir dos da década seguinte. Em 1795, as despesas totalizavam $\$ 445.719 .217$, e as receitas $\$ 479.646 .589 .{ }^{5}$ O Rio de Janeiro seguia como a segunda capitania em receitas totais, seguida pela de Minas Gerais $(\$ 516.145 .066)$ e precedida pela da Bahia (\$422.935.486) e Pernambuco (\$244.037.527). De fato, as estruturas fiscais do Rio de Janeiro parecem ter-se mantido extremamente estáveis ao longo de todo o século XVIII: suas receitas se mantinham firmemente ancoradas nas duas fontes fundamentais

5 Arquivo Histórico do Tribunal de Contas de Lisboa/Cartórios Avulsos, caixa 77: "Mapas demonstrativos da receita e despesa que tiveram as capitanias do Rio de Janeiro, Bahia, Pernambuco, São Paulo, Maranhão, Pará, Minas Gerais, Goiás, Moçambique, Goa, Ilhas dos Açores, Ilha da Madeira". 
nesse período, a saber, a dízima da Alfândega e a Casa da Moeda, que representavam cerca de metade da receita total; logo a seguir, os rendimentos dos contratos dos dízimos, do sal e da pesca da baleia.

Segundo Balbi, dos anos imediatamente anteriores à partida do rei para o Brasil a maior renda foi a de 1805 , que alcançou 11.200 contos de réis. Mas Balbi ressalvava não poder dar os detalhes, "parce que nous n'avons pas encore reçu le budget de cette année que nos correspondans de Portugal nous avaient promis". ${ }^{6}$ A respeito destas incertezas, assim se expressou o conde de Linhares, D. Rodrigo de Souza Coutinho:

"felizmente o estado verdadeiro da Fazenda Real, computando todos os seus rendimentos, tanto os que entraram no Erário como os que tiveram outras aplicações, e pondo de parte os saldos que servem à contabilidade mas que não deixam ver o resultado que se deseja, é bem diferente do que deixam ver estes balanços. Para se formar o verdadeiro estado da Fazenda Real é necessário em primeiro lugar unir em uma soma todas as rendas públicas cuja contabilidade deve ser incorporada ao Erário, onde não está. Em segundo lugar, comparar essa renda com as despesas ordinárias e extraordinárias, do ano próximo para conhecer qual é a extensão dos fundos extraordinários de que há precisão para se fazer o serviço. E finalmente compará-la com a despesa ordinária de um ano de paz, para se conhecer se a receita ordinária cobre a despesa ordinária e os recursos necessários para os fundos extraordinários e sua lenta amortização, no qual caso não há déficit e a Fazenda Real deve em poucos anos achar-se exonerada dos pesos extraordinários que possa ter."

Assim, o conde de Linhares destacava que as rendas reais nos anos finais do século XVIII alcançariam a cifra de \$9.558.348.199, com um saldo positivo de \$782.098.383.

Se estas cifras estiverem corretas, a segunda metade do século XVIII correspondeu a um período de forte incremento fiscal, já que no período de 1762 a 1776 a média das receitas ordinárias do Reino rondou os 5.220 contos. ${ }^{8}$ Obviamente, a renda das Alfândegas perma-

6 Balbi, Essai statistique (nota 2), p. 304.

7 Biblioteca Nacional do Rio de Janeiro/Divisão de Manuscritos/Coutinho, Rodrigo de Souza Coutinho, conde de Linhares: Memória apresentada ao Príncipe Regente relativa às balanças de receitas e despesas da Real Fazenda no ano de 1800. [s.l.], [1801]; 12 pp.; Coleção Portugal, I, 32, 28, 001, no. 009.

8 Fernando Tomaz, "As finanças do Estado pombalino, 1762-1776": Estudos e Ensaios 60 (1988), pp. 355-388. Os valores contabilísticos apresentados nesse trabalho foram recolhidos nos livros da receita e despesa do tesoureiro-mor, livros mestres (4 contadorias), livros de caixa do tesoureiro-mor, de 1762 a 1776, e ainda em livros de contabilidade auxiliares, custodiados pelo Arquivo do Tribunal de Contas, Fundo Erário Régio. 
necia de longe a principal fonte de recursos. Entre 1796 a 1800 esta rubrica conheceu mesmo um crescimento considerável: saltou de $\$ 3.151 .452 .896$ em 1796 para $\$ 4.177 .518 .806$ em $1800 .{ }^{9}$

\section{OS IMPACTOS FISCAIS DA TRANSFERÊNCIA DA CORTE PORTUGUESA PARA O RIO DE JANEIRO}

De fato, "sem alterar significativamente a base fiscal pré-existente, a vinda da corte justapôs ao sistema anterior um importante conjunto de impostos que trazia alterações significativas para o panorama fiscal". ${ }^{10}$ Repetindo a experiência de três séculos, a inovação fiscal limitou-se à criação de novos tributos a serem arrecadados em todas as capitanias. Em ordem cronológica de seu estabelecimento, foram os seguintes:

- Décima predial ou décima urbana (27 de junho de 1808 e 8 de junho de 1809): imposto correspondente a $1 \%$ sobre o valor venal dos imóveis das cidades, vilas e arraiais. ${ }^{11}$

- Meia sisa (3 de junho de 1809), correspondente a $5 \%$ sobre o valor de compra e venda de escravos ladinos, isto é, nascidos no Brasil.

- Décima de heranças e legados (17 de junho de 1809), correspondente a $10 \%$ ou $20 \%$ sobre o valor da herança, segundo o grau de parentesco.

- Imposto do papel selado (17 de junho de 1809 e 10 de novembro de 1810).

- Sisa, ou imposto sobre a transmissão de propriedade, correspondente a $10 \%$ do valor da compra, venda ou arrematação de bens imóveis (30 de junho de 1809).

- Imposto de indústrias e profissões (24 de novembro de 1813 e 10 de dezembro de 1814), equivalente a $\$ 12.000$ anuais sobre os estabelecimentos comerciais, e destinado a financiar o Banco do Brasil.

\footnotetext{
9 Balbi, Essai statistique (nota 2).
}

${ }^{10}$ Wilma Peres Costa, "A fiscalidade e seu avesso: centro e províncias na constituição da estrutura fiscal brasileira na primeira metade do século XIX”: Cláudia Maria das Graças Chaves/Marco Antônio Silveira (orgs.), Território, conflito e identidade (Belo Horizonte 2007), pp. 127-148, aqui: p. 134.

11 Sobre a cobrança deste imposto em Minas Gerais entre 1809 e 1835, cf. Angelo Alves Carrara, "Espaços urbanos de uma sociedade rural: Minas Gerais, 1808-1835": Varia História 25 (2001), pp. 144-164. 
Para Minas Gerais, contudo, deve ser incluído não propriamente um imposto mas um expediente financeiro que funcionou como uma forma extremamente eficiente de extração fiscal. Refiro-me à permuta do ouro em pó por bilhetes, que acompanhou o fim da circulação do ouro em pó como moeda nessa capitania. ${ }^{12}$ As ordens régias números 6 e 7 , de 2 e 7 de abril de 1808, respectivamente, ordenavam que o ouro em barra que girasse como moeda fosse levado à Casa da Moeda para ser amoedado, e davam instruções para o troco ou câmbio das barras de ouro. Quatro meses depois, o decreto de 4 de agosto mandava estabelecer no Rio de Janeiro um banco com fundo de $\$ 100.000 .000$ para permutação das barras de ouro existentes em mãos de particulares. No dia 1o de setembro seguinte era baixado o alvará proibindo o curso do ouro em pó como moeda e ordenando a circulação em todas as capitanias do interior das moedas de ouro, prata e cobre que corriam nas de beira-mar. No dia 12 do mês seguinte expediu-se o alvará regulamentando a feitura de bilhetes impressos para o troco do ouro em pó nas casas de permuta.

A imediata consequência da aplicação deste expediente foi verificado no ano seguinte: contrariando a tendência semi-secular de queda inexorável dos valores, o quinto em 1809 experimentou um salto positivo de quase $20 \%$ em relação ao ano anterior. Ora, este crescimento inopinado não se relaciona a um incremento da produção mas às conseqüências da lei de 1 o de setembro de 1808 . Se fosse mantida a média de declínio anual da produção, o quinto em 1809 deveria estar na faixa das 29 arrobas. As 20 arrobas a mais nesse ano correspondem ao ouro entesourado em Minas então permutado pelos bilhetes e moeda provincial. Nos anos seguintes, a produção seguiu a tendência normal de queda.

Apesar de todas estas medidas, ao menos para Minas Gerais, a capitania mais rentável do ponto de vista fiscal no Estado do Brasil, estas inovações tributárias não corresponderam de imediato a um incremento em suas receitas. ${ }^{13} \mathrm{O}$ impacto mais forte circunscreveu-se à capitania sede da Corte portuguesa, que da noite para o dia viu sua contabilidade fiscal pular para sete dígitos.

12 Para uma descrição detalhada de toda a série documental, cf. Angelo Alves Carrara, A Real Fazenda de Minas Gerais; guia de pesquisa da Coleção Casa dos Contos de Ouro Preto (Ouro Preto 2005), vol. 2.

13 Carrara, Receitas e despesas (nota 1). 
Os dados relativos à fiscalidade do Rio de Janeiro logo após a transferência da Corte em 1808 foram pela primeira vez apresentados por Roberto Simonsen, que os tomou de Balbi. ${ }^{14}$ A primeira inovação em matéria fiscal com a mudança da Corte foi a divisão da contabilidade geral do Império em duas: um orçamento para o Reino e outro para o Brasil e demais conquistas do ultramar. Com esta divisão, todos os gastos da Casa Real passaram a ser, naturalmente, custeados pelo orçamento brasileiro. Em 1808, estes gastos correspondiam a $20 \%$ das despesas totais, estrutura que se manteve pelo menos até o retorno de D. João VI a Portugal, em 1821 (anexo 1). Em 1820, a Casa Real respondia por $\$ 1.706 .035 .630$, de um total de $\$ 9.762 .891 .116$. O principal item de despesa era a fabricação de moedas provinciais (compreendendo a compra das piastras espanholas, de barras de cobre, etc.), que consumia $40 \%$ do total dos gastos (\$3.870.305.182).

Da parte das receitas, observa-se desde então um notável crescimento até 1820, quando o orçamento atingiu quase os 10.000 contos de réis (tabela 3 ).

TABELA 3: ReCEITAS E DESPESAS DA CAPITANIA DO RIO DE JANEIRO, 1808-1820 (EM \$)

\begin{tabular}{l|c|c|c|r}
\hline Ano & Receita & Despesa & \multicolumn{1}{c|}{ Saldo } & \multicolumn{1}{c}{ Alfândegas } \\
\hline 1808 & 2.258 .172 .499 & 2.234 .985 .204 & 23.187 .295 & 785.056 .352 \\
1809 & 2.884 .982 .183 & 2.916 .206 .687 & 31.224 .504 & 810.981 .608 \\
1810 & 5.251 .200 .524 & 5.254 .291 .164 & 3.090 .640 & 927.150 .288 \\
1811 & 3.691 .884 .485 & 3.689 .416 .406 & 2.468 .079 & 852.690 .571 \\
1812 & 3.237 .541 .397 & 3.240 .295 .820 & 2.754 .423 & 738.384 .786 \\
1813 & 4.891 .884 .932 & 4.899 .782 .139 & 7.897 .207 & 845.502 .690 \\
1814 & 4.367 .316 .580 & 4.354 .157 .650 & 13.158 .930 & 815.908 .849 \\
1815 & 4.897 .343 .597 & 4.909 .282 .441 & 11.938 .844 & 843.636 .179 \\
1816 & 5.949 .760 .503 & 5.923 .823 .069 & 25.928 .434 & 1.067 .340 .581 \\
1817 & 7.140 .109 .873 & 7.169 .944 .406 & 29.834 .533 & 1.094 .809 .251 \\
1818 & 7.949 .415 .607 & 7.923 .798 .561 & 25.617 .046 & 1.549 .123 .250 \\
1819 & 8.673 .109 .122 & 8.660 .978 .179 & 12.130 .943 & 1.976 .528 .046 \\
1820 & 9.762 .891 .116 & 9.715 .628 .699 & 47.262 .417 & 1.719 .762 .084 \\
\hline
\end{tabular}

Fonte: Simonsen, História Econômica do Brasil (nota 14), pp. 420-428.

${ }^{14}$ Roberto Simonsen, História econômica do Brasil (6a ed., São Paulo 1969), pp. 420-428; Balbi, Essai statistique (nota 2). 
Fixemo-nos na tabela 3. Em primeiro lugar, os dados mostram claramente uma curiosidade: para o Brasil, o período napoleônico não correspondeu a perdas significativas nos rendimentos da Alfândega, mas antes a uma estagnação que desaparece imediatamente após o fim das guerras, em 1815 (gráfico 1).

GrÁfico 1: Receita total e RENDimento da AlfÂNDEGa, EM CONTOS DE RÉIS. Rio DE JANEIRO, 1808-1820

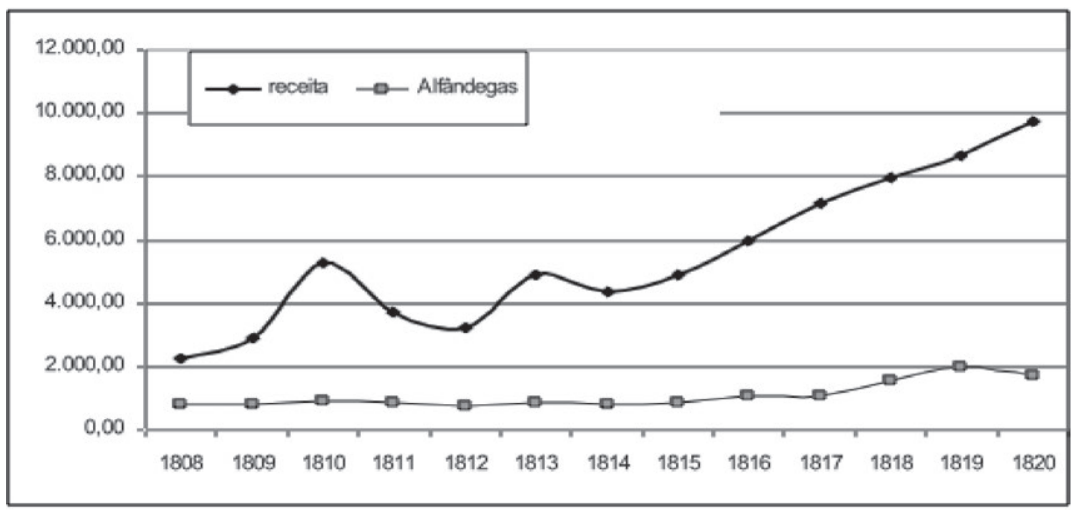

Fonte: Simonsen, História Econômica do Brasil (nota 14), pp. 420-428.

Em segundo lugar, e mais importante, a comparação entre as receitas totais do Rio de Janeiro e as do Reino revela o movimento final: a superação da arrecadação de impostos no Brasil em relação ao Reino. Em Portugal, a média das receitas e despesas do período compreendido entre 1815 e 1819 foi de \$9.758.940.000. Do lado das receitas ordinárias (\$7.194.200.000), as Alfândegas e Casas de Arrecadação participavam com a metade $(\$ 3.663 .740 .000)$, a renda do tabaco e saboarias com 20\% (\$1.373.820.000) e a décima predial com $10 \%(\$ 774.800 .000)$. A este total deve acrescentar-se a receita extraordinária, basicamente empréstimos, que no período corresponderam a uma média de $\$ 1.602 .920 .000$. A principal fonte de despesa era o Exército (\$6.042.340.000), seguido pela Marinha (\$903.100.000). ${ }^{15}$

15 Balbi, Essai statistique (nota 2), pp. 307-313. A fonte deste autor é um orçamento da receita e da despesa médias dos anos de 1815 a 1819, preparado pelo escrivão da Mesa do Tesouro Henrique Pedro da Costa e apresentado à comissão de Finanças das Cortes de Lisboa em 1821. 
Contudo, tendo em vista esta média, a ultrapassagem só ocorreu efetivamente em 1820.

Uma vez mais é nas Alfândegas que se deve buscar a causa do incremento fiscal brasileiro, acentuado ainda mais pelo movimento de exportação de café. Apesar de algo tardios, os dados disponíveis da receita total brasileira comparados aos do rendimento da Alfândega do Rio de Janeiro demonstram-no claramente: de 1828 a 1830 a Alfândega do Rio rendeu \$8.508.141.081; as receitas totais da província do Rio foi de $\$ 14.852 .933 .781$, e a de todo o Império do Brasil \$26.851.172.208. Ou seja, só o rendimento da Alfândega carioca representava $31,7 \%$ do total das receitas do Império do Brasil. Por esse tempo, as receitas totais portuguesas correspondiam a menos de sete mil contos. O que se verificou a partir dos anos 1820 foi um crescente distanciamento entre as finanças públicas brasileiras e as portuguesas. Para se ter clara idéia deste distanciamento, basta lembrar que até meados do século XIX, as receitas totais portuguesas não haviam ultrapassado os dez mil contos de réis. ${ }^{16}$

A reforçar este argumento, uma observação importante: as cifras das receitas e despesas da capitania do Rio de Janeiro entre 1808 e 1820 parecem confundir-se com as do Brasil, o que exigiria uma investigação mais detida. Se efetivamente for assim, então a fiscalidade brasileira teria já superado em muito a fiscalidade portuguesa entre 1808 e 1810.

\section{CONSIDERAÇÕES FINAIS}

No âmbito do Império português, as guerras napoleônicas determinaram a colocação em prática de uma idéia que já na primeira metade do século XVIII era cogitada em certos círculos em Portugal: a trans-

${ }^{16}$ Maria Cecília Velasco e Cruz, "O porto do Rio de Janeiro no século XIX: uma realidade de muitas faces": Revista Tempo 4, 8 (dezembro de 1999), pp. 123-148. Cf. também Adalton Franciozo Diniz, Centralização política e apropriação de riqueza; análise das finanças do Império Brasileiro no período de 1821 a 1889 (tese de doutorado, São Paulo 2002). Para as estatísticas históricas portuguesas cf. Eugénia Mata, "Finanças públicas e dívida pública": Nuno Valério (ed.), Estatísticas históricas portuguesas (Lisboa 2001) pp. 657-712; cf. também: Diretoria Geral de Estatística, Finanças; quadros sinóticos da receita e despesa do Brasil (Rio de Janeiro 1914). 
ferência da Corte para o Brasil. ${ }^{17}$ Do ponto de vista fiscal, contudo, não se pode atribuir à guerra o efeito determinante sobre o crescimento acentuado das receitas brasileiras. O que ocorre é antes uma aceleração da tendência secular de crescimento da economia brasileira, notadamente a partir dos anos finais do século XVII. As guerras napoleônicas catalisam esta tendência e desnudam o quadro efetivo de dependência da metrópole em relação a sua colônia. Em certa medida, isto é uma obviedade, seja em termos territoriais - o território brasileiro equivale a muitas vezes o de Portugal - quanto demográficos - a população de Portugal em 1811 equivalia à do Brasil. ${ }^{18}$

Se a descoberta das minas de ouro nos finais do século XVII no Brasil foi responsável pelo desenvolvimento da principal atividade econômica do Rio de Janeiro ao longo do século XVIII - o comércio, de que sua fiscalidade é nítido espelho - o século XIX tão somente consolidou este papel. Afinal, a mais importante fonte de receita do Império do Brasil continuaram sendo os impostos sobre a importação de mercadorias, para as quais o porto do Rio seguiu de longe como o mais importante.

\section{ANEXo 1}

Biblioteca Nacional, Divisão de Manuscritos, Demonstração da Receita e Despesa do Real Erário no ano de 1808 ("Mapa da receita e despesa do Real Erário do anno de 1808”); localizacão: II - 30, 27, 28; proveniente da Coleção [Antônia R. de] Carvalho.

No Catálogo da Exposição de 1881 há sob o número 6606 indicação de "balancetes do Real Erário do Rio de Janeiro, de 1808 a 1820", cujos originais se achariam no "Arquivo Público", sem dúvida, o atual Arquivo Nacional. Já sob o número 6607 há referência de originais da "receita e despesa do Real Erário do rio de Janeiro nos anos de 1808, 1809, 1810, 1812, 1817, 1818, 1819 e 1820”, em poder do Instituto Histórico. Na Biblioteca Nacional se acham os "mapas da receita e despesa do Real Erário" referentes aos anos de 1808, 1816, 1817 e 1821 [toponímico II - 30, 27, 28-31], todos provenientes da Coleção da viúva Antônia R. de Carvalho. É possível tratarem-se de diferentes vias do mesmo documento, já que a análise preliminar destes documentos mostra serem do ano imediatamente posterior ao que se referem.

${ }^{17}$ Luís da Cunha, Instruções Políticas (Lisboa 2001, original de 1736).

18 Maria Joannis Baganha/José Carlos Marques, "População": Valério, Estatísticas (nota 16), pp. 33-126, aqui: p. 33. 


\section{RECEITA (EM \$)}

\section{Receita dos rendimentos arrecadados pela Alfândega}

Direitos de $24 \%$

Receita dos rendimentos de $16 \%$ (apenas o segundo semestre)

Ditos de baldeação

Dízima e donativo

Subsídio dos vinhos, cerveja, azeite doce e aguardente do Reino e pólvora

Novo imposto do vinho, cerveja, escravos, café e aguardente

Dito do fumo (apenas o segundo semestre)

Direitos do Consulado de Lisboa, Porto, Casa da Índia, e importação de Lisboa

Direitos de Guarda Costa

Guindaste

Produtos da arrematação de gêneros na Alfândega

Subtotal

Rendimentos arrecadados pela Mesa da Inspeção

Equivalente do contrato do tabaco

Subsídio da aguardente da terra

Sal vendido por conta da Real Fazenda

Contribuição do dito

Donativo voluntário para a reedificação de Lisboa

Subtotal

Rendimentos arrecadados pelo Almoxarifado dos Armazéns Reais

Casa da pólvora na ilha de Santa Bárbara

Ancoragem dos navios estrangeiros, querenas de navios, barca da Aguada e da passagem para a ilha das Cobras

Venda de madeiras

Subtotal
511.416 .497

62.096 .448

19.687 .254

66.171 .924

49.222 .554

43.242 .652

3.437 .500

1.962 .881

27.285.650

184.480

348.512

785.056 .352

13.670.455

7.944 .322

66.521 .545

15.807 .590

40.166 .633

144.110 .545

139.590

1.431 .120

360.000

1.930 .640 


\begin{tabular}{|c|c|c|}
\hline \multicolumn{3}{|l|}{ Receita dos rendimentos arrecadados pela Alfândega } \\
\hline Rendimentos arrecadados pela Chancelaria Mor & & \\
\hline Novos ofícios e cartas de seguro & 20.038 .421 & \\
\hline Chancelaria-mor & 903.558 & \\
\hline Selo Real & 4.817 .580 & \\
\hline Subtotal & & 25.759 .559 \\
\hline Rendimentos arrecadados pela Pagadoria do Erário & & \\
\hline Donativo dos ofícios & 9.902 .384 & \\
\hline Direitos dos escravos que vão para as Minas & 22.971 .000 & \\
\hline Próprios Reais & 200.000 & \\
\hline Dízimos reais & 99.592 .427 & \\
\hline $\begin{array}{l}\text { Emolumentos das guias dos que passam para as } \\
\text { Minas }\end{array}$ & 4174800 & \\
\hline Propinas das munições de Guerra e de contractos & 2.553 .854 & \\
\hline Um por cento para obra pia & 209.500 & \\
\hline Meios soldos das patentes militares & 14.626 .335 & \\
\hline Subtotal & & 154.228 .300 \\
\hline Rendimento da Casa da Moeda & 79.463 .372 & 79.463 .372 \\
\hline Diversos rendimentos administrados e contratados & & \\
\hline $\begin{array}{l}\text { Novo imposto sobre os botequins e tavernas, } \\
\text { administrado pelas câmaras }\end{array}$ & 9.022 .000 & \\
\hline $\begin{array}{l}\text { Passagem dos rios Ururaí, Macaé e ditas dos rios } \\
\text { Paraíba e Paraibuna, contratados }\end{array}$ & 17.090 .354 & \\
\hline $\begin{array}{l}\text { Ditas do rio de São João e do registro da vila de } \\
\text { Parati, administradas }\end{array}$ & 1.058 .550 & \\
\hline $\begin{array}{l}\text { Impostos para o caminho da Serra da Estrela, } \\
\text { administrados }\end{array}$ & 5.030 .800 & \\
\hline Subsídio literário & 31.786 .346 & \\
\hline Correio, administrado & 6.845 .182 & \\
\hline Pescaria Real das Baleas dito & 3.000 .000 & \\
\hline Mestrado das três ordens militares & 5.067 .130 & \\
\hline Subtotal & & 79.700 .362 \\
\hline
\end{tabular}




\section{Receita dos rendimentos arrecadados pela Alfândega}

Receitas Extraordinárias

Cofre de depósitos

Fundos da Companhia do Alto Douro

Dons gratuitos, depósitos e empréstimos

Bens dos defuntos e ausentes, capelas e reíduos

Bula de Santa Cruzada

Venda do papel selado

Dita dos gêneros remetidos pela Junta da Fazenda da Marinha de Lisboa

Restituição feita por interveção do marquês de Belas, pertencente a Lisboa

Pagamento de suprimentos e de ordenados adiantados pelo Real Erário de Portugal

Legado deixado a S.A.R.

Extraordinárias da Alfândega

Receita militar

Remessas e sobras de diversas Juntas da Fazenda

Diversas adições: dinheiro recebido para sacar sobre Londres; entrega do almoxarife dos Armazéns Reais, ordinária restituída pelo síndico dos religiosos Franciscanos, e acréscimo de ouro na ocasião de reduzir a moeda

\begin{tabular}{|c|c|c|}
\hline Total & & 585.942 .358 \\
\hline \multicolumn{3}{|l|}{ Diversas receitas } \\
\hline $\begin{array}{l}\text { Passagem do cofre do comboio das barcas e bens } \\
\text { confiscados aos denominados Jesuítas }\end{array}$ & 72.043 .165 & \\
\hline $\begin{array}{l}\text { Banco do troco da Barras. Pela importância de } 167 \\
\text { Barras, entregues por Amaro Velho }\end{array}$ & 22.988 .524 & \\
\hline $\begin{array}{l}\text { Repartição do ouro em pó e barras. Recebido ao } \\
\text { Tesoureiro da Casa da Moeda por este artigo }\end{array}$ & 119.072 .081 & \\
\hline $\begin{array}{l}\text { Manoel Martins da Costa Passos, tesoureiro da Casa da } \\
\text { Moeda, pelo que entregou }\end{array}$ & 35.712 .096 & \\
\hline Alcances de almoxarifes e tesoureiros & 7.523 .392 & \\
\hline $\begin{array}{l}\text { Transações aos pesos castelhanos e ao desconto de } \\
\text { bilhetes }\end{array}$ & 144.641 .753 & \\
\hline Subtotal & & 401.981 .010 \\
\hline Saldo do princípio do ano de 1808 & 39.731 .600 & \\
\hline Total & & 2.297.904.099 \\
\hline
\end{tabular}




\section{Despesa (em \$)}

\section{Casa Real}

Pagadoria: entregue a Joaquim de Azevedo

Cavalariças: dito a dito 55.202.440 réis, que com 464.000 despendidos pela Pagadoria do Erário, somam

Guada Roupas: dito a dito

Casa das obras, e Paços Reais: dito a dito 38.712.040 réis, que com 31.574.819 réis de preparo do Paço e miúdas despendidas pela Pagadoria do Erário somam Ucharia: dito a José Joaquim de Matos Ferreira e Lucena

Guarda Real: dito a José de Brito

Botica: a Antônio Esteves de Mendonça

Particulares do serviço: a Francisco José Rufino de Souza Lobato, porteiro da câmara de S. A R., e seu guarda jóias, 108.507.657 réis, que com 5.431.665 reis, entregues a diversos com a mesma aplicação somam

\begin{tabular}{l} 
Subtotal \\
\hline Exército \\
\hline Soldos à tropa de mar e terra, Hospital Militar e mais \\
despesas da Tesouraria Geral das Tropas, inclusive \\
6.000 .000 réis, remetidos para a tropa de Santa \\
Catarina, e 4.759 .855 réis despendidos para o Hospital \\
pela Pagadoria do Erário
\end{tabular}

Compra de cavalos para o primeiro regimento, e de diversos instrumentos para uso da Academia Militar Trem de Guerra, e Casa das Armas

\begin{tabular}{|c|c|c|}
\hline Subtotal & & 454.638 .515 \\
\hline Marinha & & \\
\hline Soldos ao serenissímo senhor infante almirante general & 6.106 .666 & \\
\hline Almoxarifado: entregues a Pedro da Costa Leal & 231.188.049 & \\
\hline $\begin{array}{l}\text { A diversos pagamentos de gêneros, sem compreender } \\
69.453 .950 \text { réis satisfeito em saques sobre Inglaterra }\end{array}$ & 230.760 .679 & \\
\hline Pagadoria: dito a José de Souza Neto & 125.299 .671 & \\
\hline Embarcações de Guerra: compra de um bergantim & 10.499 .120 & \\
\hline $\begin{array}{l}\text { Extraordináias: pagamento de uma letra sacada de } \\
\text { Gibraltar para satisfazer as despesas ali feitas com a } \\
\text { esquadra portuguesa }\end{array}$ & 6.300 .000 & \\
\hline Subtotal & & 610.154 .176 \\
\hline
\end{tabular}




\section{Erário}

Ordenados, pensões e juros, para cujo pagamento recebeu João Carneiro de Almeida 362.554.114 réis, que com 17.969.210 réis despendidos pela Pagadoria do Erário somam

Expediente da Alfândega e Casa da Moeda

380.523.362

24.736 .291

Dito, e acomodação de diversos tribunais, inclusive o expediente da Secretaria de Estado, diversas obras, e pagamentos de cédulas

Administração Diamantina

Negócios ministeriais na corte da Dinamarca, e junto aos Estados Unidos da América

Museu

Ajuda de custo

Jóias de esponsais

Entretenimento de fábricas

Obra da Serra da Estrela

Encanamento das águas do rio Maracanã

Donativo conferido ao enviado extraordinário que foi da Corte de Londres, Manoel Martins da Costa Passos, Tesoureiro da Casa da Moeda: pelo que recebeu

22.330 .213

381.519

11.563 .480

87.680

2.776 .000

992.000

2.218 .735

76.000 .000

3.200 .000

Amaro Velho, bilhetes para desconto

80.842 .666

João Rodrigues Pereira de Almeida: dito

57.998 .096

Francisco Duarte: pagador do Erário

32.013 .620

11.830 .814

Subtotal

Despesa extraordinária

Reposição de donativos dos ofícios

Idem de Novos Direitos

Suprimentos ou despesas por conta de diversas Juntas de Fazenda

63.199 .617

Refresco à Fragata Castelhana, ... e outras despesas

Próprios reais: compra de uma chácara da banda d'além

Correio

3.965 .047

4.800 .000

\begin{tabular}{l|r|r}
\hline Subtotal & 25.720 & \\
\hline Saldo, ou maior receita no fim do ano de 1808 & & 72.327 .741 \\
\hline Total & 62.918 .895 & \\
\hline
\end{tabular}

Observação: há diferença de $\$ 3.434 .928$ para menos no total escriturado (\$2.297.904.099). 